\title{
Moeda, Tesouro e Riqueza: Uma Anatomia Conceitual do Mercantilismo Britânico do Início do Século 17
}

\author{
- Carlos Eduardo Suprinyak*
}

\begin{abstract}
RESUMO
Nossa avaliação de sistemas teóricos do passado é frequentemente prejudicada pela identificação tácita entre as categorias conceituais de ontem e hoje, problema que se agrava ao tratarmos de ideias que antecedem a plena consolidação de uma disciplina. O estudo da doutrina mercantilista costuma ser contaminado por tais dificuldades. Neste trabalho, oferecemos uma nova perspectiva acerca das ideias dos economistas britânicos do início do século 17, avaliando-as à luz do contexto intelectual que lhes é próprio. Este período caracteriza-se por uma leitura da realidade econômica em que a moeda desempenha papel fundamental. Autores como Malynes, Misselden e Mun acreditavam que a administração adequada da moeda viabilizaria o bom funcionamento do comércio internacional e dinamizaria a atividade econômica interna, garantindo a prosperidade nacional. Ao compreender esta base analítica comum, podemos entrever a origem das intensas divergências entre os autores, determinantes dos rumos da discussão teórica subsequente.
\end{abstract}

\section{Palavras-Chave}

Mercantilismo, moeda, século 17, pensamento econômico britânico pré-clássico, doutrina do balanço comercial favorável

\begin{abstract}
When evaluating theoretical systems of the past, one is frequently misled by tacitly identifying yesterday's theoretical concepts with those currently prevailing, a problem made more serious when dealing with ideas which predate the full consolidation of a discipline. Studies of mercantilistic doctrine use to be tainted by such difficulties. In the present article, we offer a new perspective regarding the ideas of seventeenth-century British economic authors, evaluating them in light of their proper intellectual context. We argue that the period is characterized by an understanding of the economic realm in which money plays a central role. Authors such as Malynes, Misselden and Mun have believed that a proper money management could assure a well-functioning international trade and dynamize domestic economic activity, guaranteeing national prosperity. Comprehending this shared analytical base, we can grasp the origins of the intense divergences among those authors, which would determine the path of subsequent theoretical debate.
\end{abstract}

\section{KEYWORDS}

Mercantilism, money, seventeenth century, pre-classical British economic thought, favorable balance of trade doctrine

\section{JEL CLASSIFICATION}

$B / I, N / 4, N 24, E 42$

\footnotetext{
* Mestre em História Econômica pela Unesp/FCLAr e doutorando em Economia pelo Cedeplar/UFMG. Endereço para contato: R. Dr. Alfredo Vieira Barcellos, 808/II, Jd. das Américas - Curitiba - PR. CEP: 8I530-560. E-mail: suprinyak@cedeplar.ufmg.br.

(Recebido em novembro de 2007. Aceito para publicação em julho de 2008).
} 


\section{INTRODUÇÃO}

Passados mais de dois séculos desde a idealização do "sistema mercantil" por obra de Smith e dos fisiocratas, falar em mercantilismo é uma tarefa, no mínimo, delicada. Capcioso como qualquer generalização histórica abrangente, o conceito de mercantilismo teve seu prestígio seguidamente abalado e restaurado pela historiografia. Desde a imprecisa formulação original de Smith, passando pela abrangência avassaladora de Hecksher até chegar ao repúdio estrito de Coleman, a ideia de mercantilismo já significou tudo e nada. ${ }^{1}$ Retomá-la, portanto, requer uma definição precisa do escopo analítico - requer que se estabeleçam de forma clara quais os limites históricos relevantes para o problema em questão.

As primeiras décadas do século 17 configuraram um período conturbado na história da Europa, em especial na Inglaterra - presságio de um século marcado por contínuas e profundas turbulências. Ao início da década de 1620, várias tendências confluíam para deflagrar uma crise econômico-social que causou comoção pública nos domínios britânicos. ${ }^{2}$ As contingências bélicas associadas à eclosão da Guerra dos Trinta Anos deram origem ao célebre fenômeno do Kipper-und Wipper-Zeit, uma série de desvalorizações metálicas nas moedas dos diversos principados do Sacro Império Romano-Germânico que visavam aumentar os recursos disponíveis para as despesas de guerra. O resultado foi um fluxo massivo de moedas de toda a Europa Ocidental em direção à região dos conflitos, atraídas pela possibilidade de ganhos na arbitragem entre valores nominais e metálicos. A Inglaterra, que vinha sofrendo com o aumento da concorrência no mercado internacional de tecidos e com o recente fracasso do Cockayne Project (que amplificou a crise na manufatura têxtil do país), sentiu de forma particularmente severa os efeitos da escassez de moeda. Já em 1621 a grande crise comercial fazia parte da pauta da Câmara dos Comuns e em 1622 uma comissão permanente foi instaurada para detectar suas causas e propor soluções.

Foi no contexto deste debate que surgiram as principais contribuições teóricas do pensamento econômico britânico na primeira metade do século. De formas distintas, os três principais autores do período estiveram envolvidos nesta discussão: Gerard de Malynes, Edward Misselden e Thomas Mun. Ao voltarem suas atenções para o estudo da crise comercial da década de 1620, estes pioneiros da análise econômica moldaram o que hoje é largamente reconhecido como a forma clássica do mercantilismo britânico. À luz destes problemas, Thomas Mun elaborou England's Treasure by Forraign Trade, seu magnum opus e obra-símbolo da doutrina mercantilista; na controvérsia acerca das medidas a serem adotadas, Malynes defendeu o par pro pari e Misselden disseminou a doutrina do balanço comercial favorável - dois conceitos

1 As referências relevantes são Hecksher (1943[1931]) e Coleman (1957).

2 Ver Gould (1954) e Supple (1959). 
fundamentais no conjunto do pensamento econômico pré-clássico. Para o bem ou para o mal, quando se recorre a uma definição de bolso do mercantilismo, são as noções predominantes neste período que vêm à tona.

Como as últimas décadas de pesquisas no campo da epistemologia nos ensinaram, conceitos científicos não são imutáveis. Ao contrário, eles evoluem conjuntamente com as teorias que sustentam, adquirindo significados que se adaptam de forma mais adequada aos problemas relevantes em determinado contexto histórico. Se tal ocorre na evolução de disciplinas científicas solidamente estabelecidas, adquire um significado ainda mais premente quando se trata de analisar as elaborações rudimentares que antecedem a consolidação teórica de determinada área do conhecimento. Embora seja impossível apreender com precisão o significado atribuído por autores do passado a determinado conjunto de conceitos, qualquer esforço historiográfico que desconsidere os vínculos contextuais de tais noções está fadado ao insucesso.

O objetivo deste artigo é oferecer uma espécie de mapa conceitual que permita apreender de forma mais verossímil as proposições que compõem o "núcleo duro" da doutrina mercantilista. Conforme indicado acima, o estudo terá um foco bastante preciso: o pensamento dos autores britânicos da primeira metade do século 17 mais especificamente, os três autores envolvidos no debate sobre a crise comercial. A guerra panfletária entre Malynes e Misselden será o suporte principal da análise, isto porque os dois autores adotaram as perspectivas antagônicas típicas do período e efetivamente debateram entre si. Observando suas divergências, podemos mais facilmente perceber quais as premissas subjacentes por eles compartilhadas.

Embora Mun goze de maior prestígio historiográfico que os demais, sua inserção no contexto do debate é problemática. O primeiro de seus dois tratados, publicado na década de 1620, é uma mera refutação de críticas dirigidas à atuação da East India Company, não possuindo grande riqueza em termos conceituais. Já England's Treasure, este sim um marco sob o ponto de vista analítico, só foi publicado postumamente, em 1664. Embora haja certo consenso quanto à relevância da crise de 1620 para sua elaboração, é difícil definir até que ponto as ideias de Mun já se encontravam então maduras, ou se, pelo contrário, foram refinadas ao longo das décadas subseqüentes. ${ }^{3}$ Assim, a obra de Mun será utilizada como um contraponto para a análise, indicando quais noções sobreviveram ao debate e merecem, portanto, ser caracterizadas como fundamentais nas reflexões econômicas do início do século.

3 Magnusson (1994) e Finkelstein (2000) apresentam divergências a este respeito. 
Antes de iniciar a discussão das ideias econômicas presentes nas obras do período, parece oportuno expor algumas breves informações biográficas acerca dos contendores que tomaram parte no debate. A preocupação destes autores com problemas econômicos decorria de seu envolvimento direto na esfera do comércio internacional britânico. Enquanto homens práticos, dotados de larga experiência em questões comerciais e financeiras, buscaram influenciar a formulação de políticas por parte dos soberanos britânicos - à época da crise, James I. Assim, suas obras assumem um caráter eminentemente pragmático, visando identificar os problemas econômicos relevantes e propor soluções concretas. Além disto, os três autores cujas obras são analisadas estiveram envolvidos, em momentos diversos, com empreendimentos comerciais detentores de patentes nacionais, assim dependendo diretamente dos arbítrios da política real - o que lhes garantiu comentários ásperos por parte de Adam Smith em sua clássica apreciação do "sistema mercantil", em que são apresentados como meros defensores de interesses estabelecidos. Seu envolvimento nos debates parlamentares que cercaram a crise demonstra de forma ainda mais contundente sua preocupação com os rumos da política econômica. ${ }^{4}$

Dentre os três autores em foco, Gerard de Malynes é aquele que possui a trajetória biográfica mais obscura. Controvérsias abundam a respeito das mais triviais informações a seu respeito, como a data de seu nascimento - na hipótese mais provável, algum momento da década de 1560 - e sua nacionalidade - embora se saiba com razoável certeza que nasceu em Antuérpia, não há consenso quanto às origens de sua família, que pode tanto ser de extração inglesa quanto holandesa. O que se sabe é que, ao longo de uma longa e prolífica carreira nos cenários comercial e financeiro da Inglaterra, Malynes adquiriu notável experiência prática na área, capacitando-o a servir, em mais de uma ocasião, como consultor da Coroa Inglesa em matérias econômicas. Já no período final do reinado de Elizabeth I, Malynes atuou como comissário de comércio da Inglaterra junto às Províncias Unidas. Sua ascendência no cenário público manteve-se durante o início do reinado de James I, quando ocupou o posto de Assay Master of the Mint - a autoridade máxima do reino em questôes monetárias. Entretanto, a carreira pública de Malynes sofreu um grande revés durante a década de 1610, após seu envolvimento com um fracassado projeto promulgado por James I que concedia uma patente para cunhagem privada de moedas de cobre,

4 Para apreciações do tema que buscam enfatizar as conexões entre as ideias econômicas destes autores e a política comercial e econômica britânica do início do século 17, bem como a participação da classe mercantil no processo de formulação destas políticas, vide Hinton (1955), Gould (1955) e Desmedt (1998). 
visando suprir as deficiências do meio circulante. ${ }^{5}$ A falência do empreendimento colocou Malynes em situação financeira delicada, incapaz de saldar suas dívidas; como consequência, acabou encarcerado na Fleet Prison durante o ano de 1619. Não obstante, seus notórios conhecimentos em matéria de comércio e finanças internacionais permitiram que prosseguisse participando ativamente dos debates na esfera pública - como membro, por exemplo, de um dos subcomitês instituídos pelo Privy Council em 1622 com o objetivo de avaliar a grande crise comercial (MUCHMORE, 1969, p. 337-339; JOHNSON, 1965 [1937], p. 42-45).

No que diz respeito à vida de Edward Misselden, os resultados alcançados até o momento pela historiografia tampouco são dignos de nota. Entretanto, seu envolvimento com algumas das mais importantes companhias comerciais britânicas do início do século 17 encontra-se satisfatoriamente documentado. Durante a década de 1610, Misselden já era membro influente dos Merchant Adventurers, participando ativamente das controvérsias que cercaram a implementação do Cockayne Project. ${ }^{6}$ Após o fracasso do projeto, e consequente restabelecimento do prestígio dos Merchant Adventurers, Misselden tornou-se o porta-voz do grupo. Nesta condição, publicou seu primeiro tratado, Free Trade or the meanes to make trade flourish (1622), obra em que procura defender a atuação da companhia, acusando a East India Company por contribuir para o agravamento dos distúrbios comerciais que então afligiam a Inglaterra. Nesta ocasião, Misselden já era membro do comitê permanente estabelecido pelo Privy Council em 1622, participando ativamente das discussões públicas em torno da crise comercial. Curiosamente, ao publicar seu segundo tratado, um ano depois, Misselden havia então estabelecido relações comerciais com a East India Company - refletindo-se esta nova situação em uma reversão completa de suas opiniões anteriores acerca das práticas da companhia. Dentre todos os envolvidos no debate, Misselden certamente é aquele cujas contribuições estão relacionadas de forma mais estreita com seus próprios interesses comerciais (JOHNSON, 1965 [1937], p. 60-61; MAGNUSSON, 1994, p. 68-69).

Por fim, resta-nos comentar brevemente a biografia do mais célebre dentre nossos autores. Como convém a sua posição de destaque, Thomas Mun é aquele sobre o qual a historiografia oferece maior riqueza de informaçóes. Mun descendia de uma longa linhagem de mercadores e financistas, legado que se preocupou em transmitir também a seu filho John - a quem dedicou a redação de England's Treasure. Em

5 Embora a patente tenha sido inicialmente concedida a John Harrington, sua morte, seis meses mais tarde, propiciou a aquisição dos direitos de emissão por parte de Malynes e William Cockayne.

6 Uma das principais medidas que compunham o projeto previa a supressão dos Merchant Adventurers, enquanto exportadores de tecidos de lã não acabados. Em seu lugar, seria instaurada uma nova companhia patenteada - os King's Merchant Adventurers - que deveria unificar o comércio de exportação de tecidos de lã da Inglaterra, permitindo que fossem negociados apenas tecidos devidamente beneficiados em território britânico (GOULD, 1954) 
1615, Mun tornou-se oficial da East India Company, à qual esteve ligado durante a maior parte de sua vida profissional. A Discourse of Trade from England unto the East-Indies (1621), sua única obra publicada em vida, trata-se de uma explícita defesa das práticas da companhia à qual servia, e que viria em breve a comandar. Sua participação nos debates do início da década de 1620 também foi intensa, sendo ele o porta-voz de um dos subcomitês instaurados em 1622. Conforme mencionado acima, embora sua obra-prima só tenha sido publicada décadas mais tarde, é certo que sua elaboração foi influenciada de forma indelével pelas reflexóes em torno da crise comercial de 1620, assim como os debates por ela engendrados (JOHNSON, 1965 [1937], p. 73-74; MAGNUSSON, 1994, p. 64, 71-72).

\section{LEITMOTIV}

Apesar de nossa obstinada fé na objetividade acadêmica, esforços analíticos são sempre informados por um quadro de referência interpretativo, próprio tanto do intérprete quanto de seu contexto histórico. Não é diferente com o problema aqui em questão. Os estudos clássicos sobre o mercantilismo foram erigidos sobre visões particulares acerca das premissas gerais compartilhadas pelos autores, visões estas que determinam, em grande medida, os resultados da análise.

Embora trate seus antecessores como uma massa informe, muito mais um ideário do que um corpo doutrinário concretamente formulado, Smith tinha uma opinião clara sobre qual o problema com o "sistema mercantil": seus adeptos não sabiam distinguir entre as noções de dinheiro e riqueza. Em função desta inépcia cognitiva, cometeram toda sorte de atrocidades analíticas, a maior de todas sendo a doutrina do balanço comercial favorável. Já Schmoller, em um contexto histórico completamente diverso, entendeu-os de outra maneira. Sobre o mercantilismo, acreditava: "em seu cerne mais intimo, não é nada além de construção do Estado" (SCHMOLLER, 1989 [1884], p. 50, tradução do autor). Assim, todas as peripécias teóricas próprias do período remetem a um objetivo maior, a unificação e consolidação dos Estadosnacionais europeus.

Com maior ou menor sucesso, Hecksher trilhou todos os caminhos analíticos abertos até então, assim como tantos outros que só agora começam a ser explorados com a devida atenção. Não obstante seu ecletismo, quando se propôs a analisar o mercantilismo enquanto sistema protecionista, também seguiu um princípio interpretativo muito claro. Para ele, o que caracteriza a política comercial externa do período - em oposição à política de abastecimento típica da Idade Média - é a ocorrência de uma "aversão às mercadorias" ( fear of goods). A disseminação da economia monetária 
turva os processos de troca e cria uma espécie de fetiche pela moeda. Combinada com a necessidade de ocupar produtivamente uma população crescente, esta ilusão monetária enseja a criação de todo um aparato político protecionista que visa incentivar exportações e restringir importações - em outras palavras, criar saldo comercial favorável.

Embora a abordagem de Hecksher seja bastante iluminadora em vários aspectos, penso que conduz a algumas dificuldades interpretativas no contexto específico da primeira metade do século 17. À guisa de exemplo, tomemos o seguinte trecho de England's Treasure by Forraign Trade:

For it is in the stock of the Kingdom as in the estates of private men, who having stores of wares, doe not therefore say that they will not venture out or trade with their mony (for this were ridiculous) but do also turn that into wares, whereby they multiply their Mony, and so by a contimual and orderly change of one into the other grow rich, and when they please turn all their estates into Treasure; for they that have Wares cannot want mony. (MUN, 1928 [1664], p. 16).

Ora, é bastante difícil conciliar esta proposição com uma suposta aversão às mercadorias subjacente à análise. Mun, Malynes, Misselden, todos eles, em vários momentos, teceram seus elogios às mercadorias e aos comerciantes, defenderam o incremento dos fluxos comerciais e a importância do comércio internacional para a prosperidade da nação. Como estes mesmos homens, eles próprios negociantes e ávidos perseguidores de lucros tipicamente mercantis, poderiam repudiar as mercadorias?

Penso que haja outra forma de apreender a rationale subjacente ao pensamento econômico britânico do início do século 17; uma alternativa que, embora preserve o sentido original da contribuição de Heckscher, torna-a mais diretamente relevante para a compreensão das obras em questão. Creio que a verdadeira aversão subjacente ao pensamento dos autores do período não seja às mercadorias em si, mas sim ao consumo das mercadorias. Embora reconheçam a importância das mercadorias para o bom transcurso das atividades comerciais, estando dispostos a defender o fomento da produção interna e também a aquisição de mercadorias no exterior para revenda, possuem uma visão essencialmente negativa do consumo final interno. Para eles, consumir é destruir riqueza. Esta noção parece contaminar as ideias de Misselden no que se refere à indústria doméstica:

We need goe no further than then the Low Countries, to learn this Lesson. [...] there you shall see no Excesse in superfluous consumption of forrain Commodities. No Projects, nor Projectors, but for the Common- 
good. All kind of Manufactures invented, that will fit the times, and please the mindes of forrain Nations. Their own Commodities eased of charge, the forraine Imposed. Frugality, industry, policy, all working together for the publicke. [...] And all these, not to breed of feed home-bred Consumption, but to maintain Trade and Forraine Negotiation. (MISSELDEN, 1623, p. 134-135, grifo do autor).

Mas Mun ainda a expressa de forma mais contundente: [T]o lose and to consume doth produce one and the same reckoning. (MUN, 1928 [1664], p. 85).

A partir desta perspectiva, torna-se fácil compreender o lugar de destaque conferido por estes autores ao comércio internacional. Se consumir é destruir riqueza, as atividades comerciais internas só podem ser estéreis, do ponto de vista nacional, pois constituem uma mera transposição de riqueza das mãos de um para as de outro. Mais uma vez, Mun apresenta a proposição de forma cristalina:

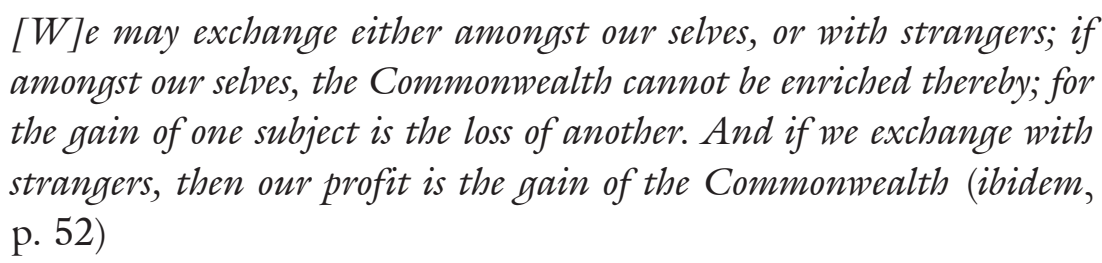

Se as transações internas não são capazes de criar riqueza, cabe ao comércio internacional a tarefa de garantir a prosperidade nacional. É importante ressaltar que estes autores não são adeptos de um ascetismo radical. Pelo contrário, acreditam que a prosperidade se manifesta, entre outras coisas, no conforto e no bem-estar dos súditos; que a natureza distribuiu as riquezas por todo o globo, de forma a induzir os povos a comerciar entre si para satisfazer suas necessidades; e que não é possível exportar muito sem importar nada, pois o comércio internacional requer certo equilíbrio nos fluxos. ${ }^{7}$ Entretanto, frugalidade e laboriosidade são as principais maneiras de garantir que, no âmbito do comércio internacional, a riqueza doméstica seja incrementada. A receita é clara: transformar o consumo estrangeiro em riqueza nacional.

Compreender tais ideias a partir da perspectiva de aversão ao consumo também permite iluminar sob outro ângulo a noção de comércio internacional como jogo de soma-zero, característica do período. Incapazes de perceber a potencialidade do

7 Tendo isto em vista, Mun defende a moderação da frugalidade: "[...] all kind of Bounty and Pomp is not to be avoided, for if we should become so frugal, that we would use few of no Forraign wares, how shall we then vent our own commodities? [...] it is more safe and sure to run a middle course by spending moderately, which will purchase treasure plentifully” (MUN, 1928 [1664], p. 60) 
mercado interno para a prosperidade, os autores do período vislumbraram de forma distorcida a dinâmica do sistema econômico. Se o consumo é transferência de riqueza, o consumo de mercadorias importadas é transferência de riqueza entre nações - a única forma possível de incremento da riqueza doméstica. Torna-se então lógica a adoção de políticas de beggar-thy-neighbour.

Também se torna mais simples, agora, compreender um dos traços mais marcantes das doutrinas econômicas do período: a ênfase sobre a moeda e a abundância doméstica de moeda. Dentro de um arcabouço intelectual que repudia o consumo e abraça o comércio internacional como única forma de alcançar a prosperidade, a moeda desempenha óbvio papel instrumental. É ela que dinamiza os fluxos comerciais; para o comerciante, é como a ferramenta para o artesão; é como o sangue que anima o corpo, "the vitall spirit of Trade". ${ }^{8}$ Faltando a moeda, o resultado certo é a decadência comercial - ergo, nacional.

A moeda ocupa o centro das discussões econômicas na Inglaterra do século 17. Tal constatação é ainda mais significativa quando se tem em conta o papel altamente subsidiário conferido à moeda pela economia clássica. Malynes, é claro, foi um especialista da matéria; analítica ou empiricamente, suas obras transbordam com temas monetários, e seu autor, de forma consistente, confia no poder da moeda como reguladora dos fluxos comerciais. Mas mesmo Misselden e Mun, defensores da primazia dos fluxos de bens, preocupavam-se essencialmente em incrementar o volume doméstico de moeda. Seus diagnósticos diferem, mas seu problema é o mesmo.

Em última instância, todas as proposiçôes econômicas do período têm por objetivo principal garantir abundância de moeda. O mercantilismo britânico do início do século 17 é um sistema monetário, e como tal deve ser abordado.

\section{MOEDA E METAIS PRECIOSOS}

Para compreender adequadamente as ideias dos autores do século 17 , é necessário um conhecimento sumário do funcionamento do sistema monetário europeu no período moderno. ${ }^{9}$ Neste período que antecede a disseminação do papel-moeda, predominava na Europa um sistema monetário bimetalista, em que ouro e prata eram efetivamente cunhados e entravam no curso das transações comerciais sob a forma de moedas. As moedas de prata, de menor valor, constituíam o principal instrumento das trocas, ao passo que as moedas de ouro eram reservadas para transações de grande porte, em

8 Misselden (1622, p. 28).

9 Embora a matéria seja complexa e os estudos especializados escassos, exposições razoavelmente satisfatórias podem ser encontradas em Vilar (1981) e Kindleberger (1993). 
especial aquelas que envolviam o transporte de moeda por longas distâncias. Cada região adotava uma taxa de conversão entre ouro e prata, que variava razoavelmente de acordo com a oferta e demanda relativas de cada metal. Dentro da Europa, esta taxa de conversão flutuava entre 10:1 e 13:1, dependendo da localidade. Entretanto, o mercado de prata encontrava-se constantemente sob pressão devido ao escoamento das moedas deste metal em direção ao Oriente - onde a cotação da prata em relação ao ouro era significativamente maior do que na Europa.

Cada moeda tinha seu valor nominal (valor de face) determinado por uma estampa real que recebia na cunhagem. Em termos ideais, este valor corrente deveria representar seu conteúdo metálico - seu valor "intrínseco". Na prática, este frequentemente não era o caso. Donos da prerrogativa da cunhagem, os soberanos com frequência utilizavam-na para obter recursos financeiros extraordinários ou mesmo para aumentar a oferta de moeda em circulação. Isto poderia ocorrer por meio de uma alteração no valor de face - o valor nominal da moeda era alterado sem mudança correspondente no conteúdo metálico; ou então adulterando a liga metálica das moedas - adicionando metais não preciosos na composição da moeda sem alterar seu valor de face. No âmbito do comércio internacional, este sistema monetário abria inúmeras vias para atividades especulativas e de arbitragem entre moedas, conforme veremos na próxima seção.

A complexidade de mecanismos deste sistema facilmente obscureceria as funçóes essenciais da moeda na esfera comercial. Todavia, os autores do período eram especialistas na matéria, e conseguiram analisá-la com bastante propriedade.

Todos eles racionalizam o surgimento da moeda da mesma forma. No princípio, era a troca de mercadorias por mercadorias, o escambo, a verdadeira natureza da atividade comercial. Com o aumento do volume de transações e, principalmente, com a inclusão de bens imóveis na esfera comercial, a operacionalização do escambo tornase excessivamente difícil. Institui-se então um padrão de valor, que servirá como eixo organizador das trocas. Embora reconheçam a possibilidade da utilização de outros padrões monetários, os autores do período defendem a adoção dos metais preciosos com base em uma característica específica: a durabilidade. Transações comerciais de dimensões variáveis justificam a utilização de mais de um metal como padrão de valor (MALYNES, 1601, p. 6-7; MISSELDEN, 1622, p. 20-21).

Assim, para estes autores, a principal função da moeda é servir como padrão de valor - ou como diria Malynes, como publica mensura. A ela cabe a responsabilidade de estruturar o sistema de trocas. Por desempenhar tão essencial função, a determinação do valor das moedas deve ser prerrogativa do soberano (MALYNES, 1601, p. 7). Entretanto, embora o valor nominal da moeda seja determinado pela autoridade 
política, os metais preciosos de que a moeda é cunhada continuam sendo mercadorias; enquanto mercadorias, têm seu valor determinado no mercado, pela interação entre oferta e demanda. Esta ambiguidade na natureza do valor das moedas criou algumas dificuldades que obscureceram as análises do período.

Tipicamente mais preocupado com questões monetárias, Malynes foi o único a encarar o problema. Defendeu com veemência superior aos demais a ideia de que a moeda determina os preços das mercadorias ("a measure and rule to set a price to everie thing”10). Mas esta "determinação", quando compreendida à luz do conjunto de suas ideias, é uma proposição trivial. O que Malynes afirma é que o nível interno de preços acompanhará alterações no valor nominal da moeda. Se o valor de face da moeda for incrementado, haverá aumento no nível geral de preços, e vice-versa. É neste sentido que o valor da moeda "determina” o valor das mercadorias.

No que se refere a alterações do nível de preços, parece seguro afirmar que os três autores aqui analisados reconhecem a importância de mudanças na quantidade de moeda em circulação. E isto não apenas no que se refere a mudanças no valor corrente das moedas, mas também no caso de flutuações na oferta de metais preciosos. Esta segunda proposição decorre diretamente da noção de que os metais preciosos são mercadorias e têm seu valor determinado no mercado. Como os metais funcionam como medida dos demais valores, mudanças em seu valor de mercado representam variações em sentido inverso nos valores das demais mercadorias - uma simples análise de preços relativos estendida ao âmbito da mercadoria padrão. ${ }^{11}$

Malynes é quem apresenta uma formulação mais clara desta ideia, mas os demais provavelmente não percebiam o funcionamento do sistema monetário de forma significativamente diversa. Se fosse este o caso, certamente teriam apontado falhas no raciocínio de seu contendor - em especial Misselden, que tantas laudas dedicou à crítica mordaz das ideias de Malynes. Vejamos como eles próprios trataram o problema:

Omitting now to speake of the finenesse, weight and proportion of the money of other countries, let us consider the property of the money, or the effects thereof; which is, that plentie of money maketh generally things deare, and scarcity of money maketh likewise generally things good cheape. Whereas things particularly are also deare of good cheape, according to the plentie or scarcitie of the things themselves, or the use of them. (MALYNES, 1601, p. 9-10).

10 Malynes (1601, p. 5).

11 Esta análise origina-se na contribuição de Bodin, herança reconhecida pelos três autores. 


\section{[A]ll men do consent that plenty of mony in a Kingdom doth make the natives commodities dearer. (MUN, 1928 [1664], p. 17).}

Assim, embora Mun e Misselden ignorem as minúcias analíticas do problema, ambos dão seu aval à noção de moeda como padrão de valor, formulada por Malynes de forma tortuosa, porém vigorosa. Fazem-no não apenas ao não criticar esta proposição a que Malynes dedica tanto empenho, mas principalmente ao adotar sem reservas - assim como seu adversário - uma versão rudimentar da teoria quantitativa da moeda. No que diz respeito aos mecanismos domésticos do sistema monetário, podemos afirmar que não há desacordo significativo entre as ideias dos três autores. Por outro lado, quando se trata de analisar o problema do câmbio, a situação é outra, bem distinta.

\section{MOEDA E CAMMBIO}

Em um período de intensificação dos fluxos comerciais internacionais, mas também de crescente tensão entre as nascentes potências europeias, transportar moedas por longas distâncias era uma atividade de alto risco. Pilhagens eram frequentes - seja por obra da iniciativa privada, ou patrocinadas pelos próprios príncipes - e representavam enormes prejuízos. Alguns instrumentos de crédito foram disseminados para amenizar o problema. No século 17, o mais popular deles, sem dúvida, foi a letra de câmbio. O princípio, bastante simples, buscava minimizar as transferências físicas de metais preciosos através de um mecanismo de compensação das transações entre os países. Ao invés de pagar por mercadorias adquiridas no exterior com moeda, os comerciantes adquiriam letras de câmbio a serem descontadas em alguma praça do exterior dentro de um determinado prazo. Nesta praça, outro comerciante que deseja adquirir mercadorias do primeiro país também adquire uma letra a ser ali descontada. Desta forma, ao invés de ocorrerem dois fluxos monetários equivalentes em sentido trocado, ocorre apenas uma mudança de mãos da moeda em suas praças de origem, passando dos importadores para os exportadores.

Conforme exposto anteriormente, as moedas correntes de cada nação têm seu valor nominal determinado pelo soberano, frequentemente não correspondendo ao seu conteúdo metálico. Desta forma, no mercado de câmbio - o mercado de letras de câmbio - surge uma cotação entre as diversas moedas internacionais, uma taxa de conversão idealmente relacionada à equivalência metálica entre elas, porém sujeita às flutuações do mercado. Além disto, certas modalidades de letras de câmbio não eram descontáveis à vista, possuindo um vencimento determinado. Neste caso, encobriam não apenas uma especulação em relação à cotação futura da moeda, mas 
também a cobrança de juros, em uma época em que a usura ainda era condenada moral e legalmente. Previsivelmente, as modalidades especulativas viabilizadas por este mercado internacional de divisas foram inúmeras.

É neste ponto, na análise positiva e normativa do mercado de câmbio, que mais se distanciam as ideias de Malynes, por um lado, e Misselden e Mun, por outro. Também é aqui que transparece de forma mais clara a confiança de Malynes no poder da moeda, em oposição à inexorabilidade dos fluxos de bens defendida por seus críticos. Em grande medida, a controvérsia da década de 1620 esgota-se no problema do câmbio.

A perspectiva de Malynes é certamente a menos característica, mas nem por isto menos incisiva. Compreendê-la é compreender todas as demais implicações atípicas de suas ideias. Em seu estilo característico, o autor acredita que o valor de uma moeda no câmbio determina os fluxos não apenas monetários, mas também os fluxos de bens - ou utilizando suas próprias palavras, "exchange is active, and commodities and money are passive” (MALYNES, 1623, p. 84). Embora cause imediato estranhamento, esta proposição está firmemente ancorada em sua percepção particular do funcionamento do mercado de câmbio.

Malynes é um crítico ácido da livre determinação do câmbio entre as moedas no mercado internacional. Para ele, a determinação do valor da moeda é uma prerrogativa do soberano; portanto, deixá-la flutuar ao sabor do mercado - manipulada por negociantes, banqueiros e especuladores - é uma atitude condenável em termos morais, uma usurpação da prerrogativa real. Se a moeda é publica mensura, alterações arbitrárias em seu valor são altamente prejudiciais à estabilidade do sistema de trocas. O "abuso" do câmbio, para Malynes, é a grande raiz da decadência comercial na Inglaterra.

Malynes acredita que a troca entre moedas deve ser realizada com base exclusiva no critério do conteúdo metálico. As taxas de câmbio devem ser ajustadas de forma a realizarem trocas equivalentes, de uma mesma quantidade de metais preciosos - o célebre conceito de par pro pari. Quando isto não ocorre, todos os demais fluxos econômicos passam a estar subordinados aos imperativos deste mercado primordial, o mercado de câmbio.

Se o câmbio corrente - o que Malynes chama de "merchandize exchange" - estiver abaixo da equivalência metálica (par pro pari), vários fatores concorrerão para ocasionar fugas monetárias do país cuja moeda está "desvalorizada” em relação ao seu valor intrínseco. Primeiramente, lembremos que as operações de câmbio constituem um instrumento que visa, precisamente, evitar os fluxos monetários internacionais. Se a 
moeda no câmbio corrente vale menos do que seu conteúdo metálico relativo, é mais vantajoso exportar as moedas em espécie, sem recorrer ao mercado de câmbio, fundilas e cunhá-las novamente na moeda estrangeira. Por meio desta operação, obtém-se uma taxa de conversão maior do que o câmbio corrente, induzindo os negociantes a efetivamente exportar as moedas nacionais (MALYNES, 1601, p. 34).

O estoque interno de moedas também será exaurido por meio de um mecanismo indireto, relacionado ao mercado de bens. Uma taxa de câmbio inferior ao par pro pari, tudo o mais constante, significa que os bens domésticos estão relativamente mais baratos no mercado internacional, ao passo que os bens estrangeiros estão relativamente mais caros. Este aumento no valor da massa de importação e diminuição do valor da massa de exportação gera ou agrava o desequilíbrio comercial, ocasionando exportação de moedas para cobrir o déficit (Note-se que, para Malynes, esta alteração nos preços relativos é perversa, não originando nenhuma possibilidade de reequilíbrio nas transações internacionais. Retornaremos a este ponto adiante). Além disto, assim como o fluxo de moedas em espécie de dentro para fora do país é lucrativo, o fluxo de fora para dentro causa prejuízos e é evitado; entretanto, como a moeda estrangeira está "sobrevalorizada" no câmbio corrente, realizar a troca também é incorrer em prejuízo. Desta forma, os comerciantes que vendem suas mercadorias no mercado internacional, ao retornar suas receitas para dentro das fronteiras nacionais, preferem fazê-lo adquirindo mercadorias estrangeiras a serem revendidas internamente - uma forma de minimizar as perdas no mercado de câmbio (MALYNES, 1601, p. 35-36; 1623, p. 17).

Em última instância, o que distingue a visão de Malynes das demais é o sentido de causalidade na organização dos mercados. Para ele, o mercado de câmbio literalmente domina os mercados de moeda e de bens - "the right course of exchange being abused, doth over-rule the course of commodities and monie." (1601, p. 17). Os fluxos de mercadorias serão sempre determinados pelas possibilidades de lucros oferecidas no mercado de câmbio. As mercadorias são as variáveis de ajuste para cobrir as transferências de moeda no mercado internacional. Podemos agora facilmente compreender sua descrença em relação ao saldo comercial favorável como forma de atrair moeda para dentro da nação; para ele, enquanto houver desequilíbrio cambial, o superávit comercial não regressará em moeda, e sim na forma de mais mercadorias estrangeiras. Para corrigir este desequilíbrio, é necessário regular oficialmente o mercado de câmbio, obrigando todas as transaçóes a serem realizadas de acordo com o par pro pari. Apenas quando isto ocorrer é que o mercado de bens estará livre para seguir o seu próprio curso (1623, p. 57-58).

Conforme indicado anteriormente, a interpretação do problema do câmbio esposada por Misselden e Mun está muito mais próxima do senso comum acerca das 
proposições mercantilistas. Sem dúvida, estes dois autores são os responsáveis pela disseminação da doutrina do balanço comercial favorável, na hipótese mais provável o principal baluarte analítico do período em questão. Não obstante, sua fé inabalável na eficácia de um saldo comercial favorável para a promoção da prosperidade nacional está relacionada a outra crença, mais profunda e sutil: a ideia de que é o mercado de bens que determina, em última instância, os rumos da atividade econômica, e que as demais variáveis apenas se ajustam para seguir o seu curso. Esta noção está substancialmente mais próxima da abordagem característica da escola clássica; sabemos que, a médio e longo prazo, prevaleceu. Mas durante a década de 1620 a vitória não estava assegurada, e para alcançá-la foi preciso lutar.

A verdade é que Misselden, que foi quem esteve envolvido diretamente na controvérsia, não parecia ainda confiar tão cegamente na ascendência absoluta dos fluxos de bens. Tanto é que postulou, como causa imediata da fuga de moedas da Inglaterra, a "subvalorização" da moeda inglesa nos mercados internacionais - não a taxa de câmbio abaixo do par pro pari, mas sim o baixo valor nominal da moeda inglesa em relação às demais, sua correspondência mais estreita com o conteúdo metálico (MISSELDEN, 1622, p. 7-8). Entretanto, Misselden começa a se distanciar da abordagem "monetária" de Malynes ao argumentar que o mercado de câmbio, sendo um mercado como qualquer outro, deve se orientar pela interação entre a oferta e a demanda de divisas internacionais. O câmbio é apenas um reflexo das condições deste mercado: [I]t is not the rate of Exchanges, but the value of monies, here lowe, elsewhere high, which cause their Exportation: nor doe the Exchanges, but the plenty or scarcity cause their values. (idem, ibidem, 1622, p. 104).

Da mesma forma, o mercado de bens tem suas próprias regras, independentes do mercado de câmbio:

[I]t is not the rate of Exchanges, whether it be higher or lower, that maketh the price of comodities [sic] deare or cheape, as Malynes would here inferre; but it is the plenty or scarcity of Commodities, their use or Non-use, that maketh them rise and fall in prices. (idem, 1623, p. 21, grifo do autor).

Assim, para Misselden, a única forma eficaz de garantir o afluxo doméstico de moedas é por meio de medidas que atuem sobre o mercado de bens: fiscalização da qualidade dos tecidos exportados (1622, p. 128); redução do volume de litígios e das custas processuais na esfera comercial (ibidem, p. 29-30); diminuição das taxas de juros (ibidem, p. 117); reestruturação da carga tributária, aliviando a pauta de exportações e onerando a de importações (ibidem, p. 50); restrições ao consumo de 
bens supérfluos (estímulo à frugalidade) (ibidem, p. 108; 1623, p. 132); estímulo a indústria doméstica (1623, p. 132).

A defesa da supremacia do mercado de bens encontra seu expositor mais vigoroso em Thomas Mun. Isto fica claro já no início de sua defesa da East India Company, publicada em 1621, em que define o comércio de mercadorias como "the touchstone of a kingdomes prosperity" (MUN, 1621, p. 1). Os capítulos XII, XIII e XIV de England's Treasure são dedicados a uma crítica explícita às ideias de Malynes acerca dos mecanismos do mercado de câmbio. Como Misselden antes dele, Mun propóe que o mercado de câmbio é determinado pela oferta e demanda de moedas nas diversas praças internacionais: [T] hat which causeth an under or overvaluing of moneys by Exchange, is the plenty or scarcity thereof in those places where the Exchanges are made. (MUN, 1928 [1664], p. 39).

Ao contrário do que postulava Malynes, Mun acredita que o mercado de câmbio seja uma forma de regular os fluxos monetários de forma a compensar as transações comerciais. A demanda por câmbio entre duas localidades quaisquer está diretamente relacionada ao saldo comercial entre elas; se uma nação incorre em déficit comercial com outra, a necessidade de cobrir este déficit com remessas de moeda causará uma pressão de demanda pela moeda estrangeira no mercado de câmbio, "desvalorizando" a moeda nacional. Não há fluxos monetários permanentes sem que haja também desequilíbrio comercial:

As plenty or scarcity of mony do make the price of the exchange high or low, so the over or under balance of our trade doth effectually cause the plenty or scarcity of mony. [...] the monies which are carried from us within the balance of our trade are not considerable, for they do return to us again: and we lose those monies only which are made of the over-balance of our general trade, that is to say, That which we spend more in value in forraign wares, than we utter of our own commodities. And the contrary of this is the only means by which we get our treasure. In vain therefore hath Gerard Malines laboured so long, and in so many printed books to make the world believe that the undervaluing of our money in the exchange doh exhaust our treasure, which is a mere fallacy of the cause, attributing that to a Secondary means, whose effects are wrought by another Principal Efficient, and would also come to pass although the said Secondary means were not at all. (idem, ibidem, p. 40-42, grifo do autor) 
Assim, Mun expõe de forma clara sua percepção do ordenamento dos mercados, cerne da oposição irreconciliável entre suas ideias e as de Malynes, como ele próprio reconhece:

\begin{abstract}
[T] he profit and loss upon the Exchange is guided and ruled by the over or under balance of the several Trades which are Predominant and Active, making the price of Exchange high or low, which is therefore Passive, the contrary whereof is so often repeated by the said Malynes. (ibidem, p. 49, grifo do autor).
\end{abstract}

\title{
6 MOEDA E RIQUEZA
}

O problema do câmbio encerra grande parte da divergência entre as proposições de Malynes, Misselden e Mun; no restante de suas ideias, o que vemos são derivações desta divergência fundamental ou então uma simples concordância tácita. Ao analisar o mercado de câmbio, os autores estavam preocupados em encontrar maneiras de garantir um abastecimento interno satisfatório de moeda. Resta-nos, ainda, explorar uma questão mais fundamental para a compreensão do pensamento econômico do período: por que, afinal, era tão importante atrair moeda? Na resposta a esta pergunta, os contendores de ambos os lados parecem estar bem próximos do acordo.

Desde que Smith impingiu aos mercantilistas o pecado original de confundir moeda com riqueza, esta tem sido uma acusação frequente, até mesmo trivial, em exposições sumárias do período. Entretanto, neste caso talvez mais do que em qualquer outro, uma apreciação atenta da estrutura conceitual das obras revela uma compreensão do tema muito mais rica do que se poderia imaginar. $\mathrm{O}$ mais breve contato com as produções intelectuais do período torna implausível a tese de que, para estes autores, os conceitos de moeda e riqueza eram equivalentes.

Primeiramente, é importante destacar a existência de dois conceitos próximos, porém distintos: tesouro (treasure) e riqueza (wealth). O primeiro deles refere-se à moeda e aos metais preciosos acumulados por uma nação - ao seu estoque metálico, propriamente. Já o conceito de riqueza, embora sempre formulado de maneira imprecisa, remete a um conjunto muito mais amplo de atributos, que englobam as possessões metálicas, mas também envolvem o que os autores chamam de artificial e natural riches: os recursos naturais e as manufaturas domésticas. Passagens em que as noções de tesouro e riqueza são claramente dissociadas podem ser encontradas em profusão em qualquer obra do período. Mun afirma que a manufatura de tecidos constitui "the greatest Wealth and best Employment of the Poor of this Kingdome" (MUN, 1928 
[1664], p. 73). De forma semelhante, ao discutir a atividade de pesca levada a cabo pelos holandeses em costas inglesas, Misselden afirma:

[N]ot only the bread is taken out of our subjects Mouth, but that in-
finite Wealth, which God hath made Proper and Peculiar unto Us,
is become Common unto them. (MISSELDEN, 1622, p. 35, grifo
do autor).

Algumas proposições típicas do estilo inflamado destes autores induzem uma sensação contrária. Malynes, ao falar dos efeitos deletérios do câmbio abaixo do par, lista entre eles: "decrease of our wealth, o exportation of our monies" (1601, p. 16). Esta enumeração dos dois fenômenos lado a lado cria a impressão de que são equivalentes; porém notemos, antes disso, que o autor teve o cuidado de distingui-los. Em outra parte, o autor afirma que a diminuição da riqueza só pode ocorrer por meio da exportação de moedas ou de um saldo comercial desfavorável. Esta vinculação entre flutuações de riqueza e saldo comercial também é frequente nas obras de Misselden e Mun. Como explicá-la?

Retomemos a ideia apresentada na segunda seção, que propunha compreender o mercantilismo britânico do início do século 17 como um sistema de aversão ao consumo. Sob este prisma, é fácil perceber que, no pensamento da época, embora moeda e riqueza não sejam conceitos idênticos, a moeda necessariamente deve ser a forma privilegiada assumida pela riqueza. Conforme dizíamos acima, os autores do período não repudiavam as mercadorias; pelo contrário, estimulavam o comércio de mercadorias e até mesmo a exportação de moedas para aquisição destas. Entretanto, como entendiam o consumo de mercadorias como destruição de riqueza, as mercadorias importadas deveriam necessariamente ser reexportadas. As mercadorias constituem riqueza, posto que os lucros da operação comercial estão nelas embutidos. Porém, a condição para que se confirme sua condição de riqueza é que não sejam consumidas internamente, e sim vendidas ao exterior. Se o pagamento vier na forma de outras mercadorias, a riqueza continua presente nelas de maneira latente, talvez até incrementada. Este processo só terá fim quando a riqueza contida nas mercadorias for finalmente realizada, convertendo-se em moedas - o risco do consumo interno deixando então de existir.

Esta é a solução, digamos, analítica do problema da importação de moeda. Mas há outra razão, mais instrumental e pragmática, que torna compreensível a ânsia dos autores do período pela abundância monetária interna. Além de representar a forma "definitiva" da riqueza, a moeda possui, em sua visão, uma função ativa: dinamizar a atividade comercial. É neste sentido que a moeda, para o comerciante, é como a 
ferramenta para o artesão; é neste sentido que a moeda é como o sangue que anima o corpo:

Or will any man think that Trade can be driven conveniently without moneys and exchanges? will not the want of it make a dead Trade within the Realme when this Vitall Spirit of Commerce faileth? surely it is questionles in every mans understanding. (MALYNES, 1623, p. vii).

[H] is majesties Kingdomes and Dominions will flow with Bullion and Moneys, and infuse life thereunto. (ibidem, p. viii).

[B]y which plenty of money there will be a lively Trade... (ibidem, p. $51)$.

For Money is the vitall spirit of trade, and if the Spirits faile, needes must the Body faint. And as the Body of Trade seemeth to be Dead without the Life of Money: so do also the Members of the Commonwealth without their Meanes of Trade. (MISSELDEN, 1622 , p. 28, grifo do autor)

[I]t is much better for the Kingdome to have things deare with plenty of Money, whereby men may live in their severall callings: then to bave things cheape with want of Money, which now makes every men complaine. (ibidem, p. 107, grifo do autor)

Os trechos acima transcritos demonstram de forma clara a confiança depositada na abundância de moeda como mecanismo de estímulo à atividade comercial. Aliás, os estímulos não se limitam à esfera do comércio internacional: Mun aponta efeitos subsidiários sobre os preços de bens intermediários, as rendas e o preço da terra (MUN, 1928 [1664], p. 21), e instiga o soberano a promover a circulação monetária por meio de gastos internos (ibidem, p. 68-70). Se a moeda é o sangue do corpo político, a circulação não pode parar.

Mas há ainda outra noção elusiva que me parece importante para alcançar uma compreensão plena do problema em questão. Refiro-me ao conceito de stock, recorrentemente utilizado por nossos autores, porém nunca definido de forma explícita. A utilização do conceito de forma abrangente e em diversos contextos distintos induz a imaginar que estamos próximos de uma formulação rudimentar do conceito moderno de capital. Por outro lado, a despreocupação dos autores em defini-lo de forma precisa indica que esta seria uma conclusão precipitada: o conceito de stock, ao que parece, representa uma noção mais intuitiva, menos analítica. 
Por vezes, o termo é utilizado em um sentido corriqueiro, aludindo simplesmente ao estoque de mercadorias e moedas nas mãos dos comerciantes. Com esta conotação, Misselden lamenta o embargo holandês às embarcações da East India Company: "the Common-wealth hath lost the use and employment of the Stocke itselfe, and all the encrease of Trade which the same might have produced" (1622, p. 14). Entretanto, seu sentido mais frequente alude a uma ideia ampla, abrangente; refere-se ao complexo das possessões materiais de uma nação. Alguns exemplos ajudarão a ilustrar a forma em que os autores utilizaram-no, bem como sua relação com outros conceitos:

[T] he more the stocke of Christendome is thebreby encreased in Wares, the more it decreaseth in Treasure. (MISSELDEN, 1622, p. 21, grifo do autor)

[T] he Trade from England to the East-Indies doth not consume, but rather greatly increase the general stocke and Treasure of this Realm. (MUN, 1621, p. ii-iii).

For although the East-India Company shall disburse the greatest part of the sayd somme [...] for custom and impost, and also unto the Factors, Officers, and Mariners, for wages, together with the cost of shipping, Victuals, Munnitions, Assurance and the like; yet all these (the Materialls of Shipping onely excepted) are but transmutations, and no consumption of the Kingdomes stocke. (idem ibidem, p. 24).

[T] he encrease of the stocke of the Kingdom is very great: [...] the same is a meanes to bring in much Treasure. (MISSELDEN, 1623, p. $38)$.

If the Native Commodities exported doe waigh downe and exceed in value the forraine Commodities imported; it is a rule that never faile's, that then the Kingdome growe's rich, and prosper's in estate and stocke: because the overplus thereof must needs come in, in treasure. But if the Forraine Commodities imported, doe exceed in value the Native Commodities exported; it is a manifest signe that then trade decayeth, and the stocke of the Kingdome wasteth apace: because the oveplus must needs goe out in treasure. (idem ibidem, p. 117).

The revenue of stock of a Kingdom by which it is provided of forraign wares is either Natural or Artificial. (MUN, 1928 [1664], p. 7, grifo do autor). 
Chama atenção a ligação entre treasure e stock nas proposições de Misselden. É nelas, e em outras similares, que podemos entrever algo parecido com uma noção de capital. Se o ingresso de tesouro causa incremento no stock, que por sua vez pode proporcionar novos ingressos de tesouro, parece haver aí uma ideia de circulação produtiva da riqueza induzindo a prosperidade nacional. Misselden, ao sugerir a instauração de uma oficina para emprego dos pobres, propõe "to raise a stocke, out of the free will offerings of the Citizens” (1623, p. 137). O seguinte exemplo, oferecido pelo próprio Misselden, reforça ainda mais a ideia:

\section{[T] he Trade of the Kingdome, may thereby be encreased, in Stock, in Strenght. In Stock: for one hundred thousand pounds imployed in that trade, and returned from the East Indies, in Spices, Callicoes of Indico [...] will yield five hundred thousand pounds to this Kingdome, in encrease of Stocke. (ibidem, p. 35, grifo do autor)}

Embora suficientes para destacar a função ativa associada ao conceito de stock, os exemplos enumerados oferecem apenas uma imagem fragmentária de seu significado pleno. Extrapolá-los para uma proposição mais abstrata envolve razoável volume de conjecturas. Minha impressão é a de que a ideia de stock ocupa um lugar intermediário entre os dois conceitos explorados anteriormente, tesouro e riqueza. Embora esteja mais próxima da noção de riqueza, diferencia-se dela por remeter apenas àquela parcela dos recursos nacionais pronta para ingresso imediato no circuito comercial a riqueza, como vimos, inclui todos os recursos potenciais da nação, como os peixes no oceano à espera dos pescadores. Entretanto, o stock possui outra natureza; não é apenas um conceito menos abrangente do que a riqueza, mas também qualitativamente diverso. Funciona como um mediador entre o tesouro e a riqueza, impedindo que a riqueza se concentre em uma forma estática e, neste processo, garantindo seu incremento progressivo e cumulativo. É neste sentido que a noção de stock pode fazer parte da linhagem genealógica do conceito de capital. ${ }^{12}$

\section{FLUXOS INTERNACIONAIS}

As proposições mercantilistas, em especial a doutrina do balanço comercial favorável, frequentemente são criticadas a partir da perspectiva oferecida pelo specie-flow

12 Note-se, de passagem, que a racionalização da doutrina do balanço comercial favorável proposta por Keynes ao final da Teoria Geral passa pela consideração dos rendimentos mercantis obtidos na esfera do comércio internacional como formação de capital potencial - em uma economia na qual não há instrumentos para manipulação direta da taxa de juros doméstica, o único mecanismo de estímulo ao investimento disponível é a persecução de um excedente comercial com o exterior (KEYNES, 1936, p. 333-349) 
mechanism, instrumento analítico elaborado com precisão por Hume em meados do século 18. Ao defenderem uma acumulação indiscriminada de moeda, os autores do período teriam ignorado o funcionamento dos mecanismos automáticos de ajuste no mercado internacional, atuando por meio de alterações nos níveis relativos de preços. O objetivo desta seção é mostrar sucintamente que, no caso do pensamento britânico do início do século 17 , este não é o caso. Nossos autores não ignoraram o problema: quando não o enfrentaram, foi porque ele simplesmente não fazia parte de sua problematização.

Neste tópico, voltamos a testemunhar uma divergência profunda entre as interpretações de Malynes e Misselden/Mun. Começaremos analisando a formulação do primeiro. Para reconhecer o funcionamento do specie-flow mechanism, é necessário conjugar a ação de dois princípios analíticos: a teoria quantitativa da moeda e a existência de demandas preço-elásticas pelas mercadorias transacionadas internacionalmente. Já vimos anteriormente que Malynes, assim como Misselden e Mun, reconhece e aceita uma versão rudimentar da teoria quantitativa; o que não aceita, por outro lado, é a elasticidade-preço da demanda. E sua rejeição não resulta de um desconhecimento do princípio $^{13}$, pelo contrário: Malynes acredita firmemente que a demanda pelos produtos ingleses no mercado internacional não é afetada por alterações nos preços. Daí advém sua exortação, estranha a ouvidos modernos, à manutenção de preços domésticos altos e preços estrangeiros baixos: To the generall objection, that selling our commodities dearer, would be an interruption to the traffique, we have already showed how necessary our commodities are, o what request thereof is in all places. (MALYNES, 1601, p. 117-118).

Para ele, o saldo comercial é determinado em grande medida pelos preços das mercadorias; as quantidades negociadas são dadas - razoavelmente fixas, ao menos no que se refere a flutuações de preço (ibidem, p. 12). Além disto, há outro agravante. Lembremos da predominância atribuída por Malynes ao mercado de câmbio; se os fluxos monetários são determinados no mercado de câmbio, e não no mercado de bens, o mecanismo de autoajuste torna-se estéril (ibidem, p. 35-36).

Embora discorde de Malynes no que tange à primazia do mercado de câmbio sobre os fluxos monetários, Misselden também acredita na inelasticidade da demanda internacional pelas mercadorias inglesas - embora reconheça o acirramento da competição nos mercados internacionais de tecidos $(1622$, p. 41$)$. Desta forma, ele também pôde descartar os efeitos inflacionários perniciosos do acúmulo de moeda. Mun, por

13 Obviamente, os autores do período nunca utilizaram nenhum conceito analítico preciso para abordar o problema. Entretanto, suas discussões acerca da dependência da demanda (vent) nos mercados internacionais com relação aos preços dos bens são bastante explícitas, também nas obras de Malynes e Misselden, mas especialmente com Mun. 
outro lado, tendo a crise da década de 1620 em perspectiva, já não acreditava que as mercadorias inglesas fossem tão indispensáveis nos mercados europeus:

In our exportations we must not only regard our own superfluities, but also we must consider our neighbours necessities, that so upon the wares which they cannot want, nor yet be furnished thereof elsewhere, we may [...] gain so much of the manufacture as we can, and also endeavour to sell them dear, so far forth as the high price cause not a less vent in the quantity. But the superfluity of our commodities which strangers use, and may also have the same from other Nations, or may abate their vent by the use of some such like wares from other places, and with little inconvenience; we must in this case strive to sell as cheap as possible, rather than to lose the utterance of such wares (MUN, 1928 [1664], p. 8).

Por reconhecer a existência de uma relação inversa entre a demanda pelas mercadorias inglesas e seus preços, Mun não pôde defender sem reservas o acúmulo doméstico de moeda. Sua solução para o problema, embora de eficácia questionável, integra-se harmonicamente com o restante de suas ideias. Para evitar os efeitos nocivos do aumento no nível de preços, é necessário manter o dinheiro em circulação - não apenas internamente, mas também na esfera internacional, liberalizando a exportação de moeda no exercício do comércio:

If wee were once poor, and now having gained some store of mony by trade with resolution to keep it still in the Realm; shall this cause other Nations to spend more of our commodities than formerly they bave done, whereby we might say that our trade is Quickened and Enlarged? No verily, it will produce no such good effect: but rather according to the alteration of times by their true causes we may expect the contrary; for all men do consent that plenty of mony in a Kingdom doth make the native commodities dearer, which as it is to the profit of some private men in their revenues, so it is directly against the benefit of the Publique in the quantity of the trade; for as plenty of mony makes wares dearer, so dear wares decline their use and consumption [...]; And although it is a very hard lesson for some great landed men to learn, yet I am sure it is a true lesson for all the land to observe, lest when wee have gained some store of mony by trade, wee lose it again by not trading with our mony. (ibidem, p. 17). 
A solução vislumbrada por Mun para o problema da acumulação de moeda demonstra mais uma vez a complexa interação de noções como as de tesouro, riqueza e stock, dando consistência às construções intelectuais típicas do período.

\section{LIBERDADE COMERCIAL}

Por fim, gostaria de comentar brevemente a noção de liberdade comercial presente nos escritos da época. Para alguém acostumado a pensar no mercantilismo como uma doutrina impregnada de intervencionismo e gerência estatal, certamente causará surpresa deparar-se com obras intituladas de forma tão sugestiva quanto o tratado de Misselden, Free Trade or the meanes to make trade flourisheth, ou então a resposta de Malynes, The Maintainance of Free Trade. No corpo destas obras também abundam referências à "liberdade natural", ou ao "curso natural", do comércio. Mas estas apologias podem ser altamente ilusórias. A este respeito, acredito que a interpretação de FINKELSTEIN (2000) seja essencialmente correta. Em England's Treasure, Mun por vezes se aproxima de uma defesa mais pura da liberdade comercial, postulando a inexorabilidade dos fluxos econômicos - em especial quando critica o Statute of Employment (1928 [1664], p. 34-37). Entretanto, o que Malynes e Misselden têm em mente ao falar de liberdade comercial é algo muito mais restrito: coibição dos excessos produzidos pelo mercado (em especial os monopólios), mas sempre dentro da órbita de um comércio apropriadamente organizado, regulado e supervisionado pelo Estado. Embora os autores do período costumem louvar as virtudes da liberdade comercial, a expressão não deve ser tomada por seu valor de face.

\section{CONCLUSÃO}

O objetivo principal deste artigo não é oferecer uma nova interpretação da doutrina mercantilista, mas sim colocar as ideias econômicas surgidas na Inglaterra do início do século 17 em seu lugar correto por meio de uma apreciação adequada da estrutura conceitual utilizada pelos autores que as desenvolveram. Porém, como dito no início da terceira seção, não é possível analisar uma contribuição intelectual em perspectiva histórica sem o auxílio de um quadro de referência interpretativo. No decorrer da exposição, colocamos em evidência o papel central desempenhado pela moeda nas diversas reflexões econômicas do período; procuramos, conforme esta constatação, analisar tais construções em sua relação com o conceito fundamental de moeda. A noção de aversão ao consumo parece bastante fértil como forma de conferir consistência ao todo, estruturando e conectando as diversas ideias então surgidas. Acredito ter oferecido evidências de que, embora certamente prejudicado por uma estrutura 
conceitual rudimentar, o pensamento dos autores britânicos do início do século 17 possui maior coerência interna do que se costuma supor, além de estar intimamente vinculado ao enfrentamento dos problemas econômicos relevantes no período.

\section{REFERENCIAS}

COLEMAN, Donald C. Eli Hecksher and the idea of mercantilism. Scandinavian Economic History Review, v. 5, 1957.

DESMEDT, Ludovic. La 'sagesse pratique' des premiers mercantilistes anglais: l'analyse du change et du commerce exterieur au début du XVIIe siècle. LATEC - Document de Travail - Economie, Université de Bourgogne, n. 8, 1998.

FINKELSTEIN, Andrea. Harmony and the Balance: an intellectual history of seventeenth-century economic thought. Ann Arbor: University of Michigan Press, 2000.

GOULD, J. D. The trade depression of the early 1620's. Economic History Review, Second Series, v. VII, n. 1, p. 81-90, 1954.

. The trade crisis of the early 1620's and English economic thought. Journal of Economic History, v. 15, p. 119-133, 1955.

HECKSCHER, Eli. La época mercantilista: historia de la organización y las ideas econômicas desde el final de la edad media hasta la sociedad liberal. México: Fondo de Cultura Económica, 1943.

HINTON, R. W. K. The mercantile system it the time of Thomas Mun. Economic History Review, New Series, v. 7, n. 3, p. 277-290, 1955.

JOHNSON, E. A. J. Predecessors of Adam Smith: the growth of British economic thought. New York: Augustus M. Kelley Publishers, 1965.

KEYNES, John Maynard. The general theory of employment, interest and money. London: Macmillan and Co., 1936.

KINDLEBERGER, Charles P. A financial history of Western Europe. New York, Oxford: Oxford University Press, 1993.

MAGNUSSON, Lars. Mercantilism: the shaping of an economic language. London/ New York: Routledge, 1994.

MALYNES, Gerrard. A Treatise of the Canker of England's Common Wealth. Edição fac-simile. London, 1601.

. The Center of the Circle of Commerce. Edição fac-simile. London, 1623.

MISSELDEN, Edward. Free Trade or the meanes to make trade flourish. Edição facsimile. London, 1622.

. The Circle of Commerce or the Balance of Trade, in defence of free trade, London, 1623, edição fac-simile. 
MUCHMORE, Lynn. Gerrard de Malynes and mercantile economics. History of Political Economy, v. 1, p. 336-358, 1969.

MUN, Thomas. A Discourse of Trade from England unto the East Indies. Edição facsimile.London, 1621 1928.

England's Treasure by Forraign Trade, Reprinted: Oxford: Basil Blackweel,

SCHMOLLER, Gustav. The mercantile system and its historical significance. Fairfield: Augustus M. Kelley Publishers, 1989.

SMITH, Adam. The Wealth of Nations. New York: Random House, Inc., 1937.

SUPPLE, Barry E. Comercial crisis and change in England, 1600-1642. Cambridge Mass.: Cambridge University Press, 1959.

VILAR, Pierre. Ouro e moeda na bistória, 1450-1920. Rio de Janeiro: Paz e Terra, 1981. 